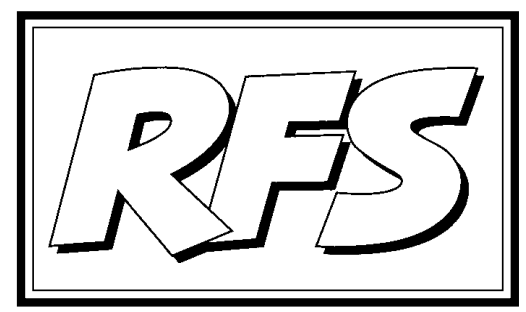

Revista de Fomento Social, 58 (2003), 11-34

\title{
Acción política y comportamiento de los católicos en España
}

\section{Consejo de Redacción}

En nuestro actual momento político vivimos una interesante situación que tiene algo de paradójico. Por una parte se observa un renovado interés por las cuestiones públicas, que aflora precisamente después de estos últimos diez años en que la prioridad de la política de los sucesivos Gobiernos españoles ha sido la convergencia económica europea. Por otra, en el mundo cristiano hay algunos claroscuros. Frente a cierta atonía eclesial en relación con lo político, y a la "mala imagen pública de la Iglesia" que trasmiten muchos medios, renace el interés público ante las tomas de posición de la Iglesia, para bien o para mal, como ha ocurrido en los casos recientes del nacionalismo vasco, la condena del terrorismo, la cuestión educativa y, últimamente, la reacción ante la crisis de Irak. En el mundo cristiano la política encuentra un lugar especial, bien por el compromiso explícito y duradero de muchos cristianos en los procesos de transformación social, en el Cuarto Mundo, o en la cooperación al desarrollo del Sur, bien por la sensibilidad siempre creciente del catolicismo evangélico hacia el compromiso por otro mundo posible. En una palabra, parece que el interés por lo político y el compromiso cristiano se reavivan. Ello es una buena ocasión para abordar el tema que nos hemos propuesto para este editorial. 
Al hacer nuestra reflexión sobre la acción política y el comportamiento de los católicos en España, descartamos abordar cuestiones más generales, como las relaciones entre Iglesia y política, la vocación política del cristiano en general, o las relaciones entre los partidos políticos y la jerarquía eclesiástica en España y sus conflictos o convergencias coyunturales. Pretendemos, más bien, una reflexión aplicada a nuestra actual situación española, en una doble dirección: la relación real de los partidos políticos con el catolicismo en España, y la presencia y actuación de los católicos en los diferentes partidos políticos españoles y en las instituciones políticas básicas ${ }^{1}$. Por otra parte, considerar que el factor católico juega un papel en la vida política e influye, como tal factor, en la acción política no es algo obvio: por ello no podemos eludir algunas consideraciones sobre esta cuestión, capaces de suscitar un debate más amplio.

\section{Signos de nuestro tiempo}

Al abordar la relación entre la acción política y el factor católico no podemos dejar de decir algo sobre algunos fenómenos recientes que afectan a la política y a su relación con la religión. Al enumerarlos, no pretendemos hacer un diagnóstico completo de nuestro tiempo, sino sólo destacar aquellas tendencias que creemos de mayor interés para ilustrar nuestras reflexiones.

A) El período que ha seguido a la caída del muro de Berlín ha provocado una reconfiguración del mundo, que ha llevado a un nuevo papel de los

1 El propio proceso de elaboración de las páginas que siguen ilustra sobre nuestra pretensión. El Consejo de Redacción de la Revista ha tenido ocasión de celebrar en ETEA dos sesiones específicas de seminario, con personas significativas a las que habíamos invitado, encaminadas a enriquecer nuestras propias ideas sobre el tema del editorial. El día 17 de enero nos reunimos con Ramón Jáuregui, diputado del PSE en el Congreso de los Diputados y vicepresidente del Gobierno Vasco hasta 1998, así como con Carlos García de Andoin, militante cristiano y miembro asimismo del PSE. Intercambiamos ideas sobre la mutua relación entre socialistas y cristianos en el actual contexto español. De igual modo, el día 10 de febrero nos reunimos con Amalia Gómez, militante del PP y exsecretaria general de Asuntos Sociales en el Ministerio de Trabajo y Asuntos Sociales: este encuentro nos permitió conocer más de cerca la experiencia y motivaciones de la concreta implicación en política activa de una persona que se confiesa cristiana. A ellos y a los compañeros, profesores de ETEA que participaron en las sesiones, expresamos nuestro sincero agradecimiento por su colaboración. Ni que decir tiene que las reflexiones que siguen no pretenden reflejar las opiniones de nuestros invitados, sino que son de la exclusiva responsabilidad del Consejo de Redacción de la Revista. 
Estados Unidos en la política mundial como "potencia única". Importantes son los procesos, más conocidos y comentados, de la globalización económica y sus innumerables consecuencias (entre las que cabe mencionar la multiplicación de los movimientos migratorios y el surgimiento del terrorismo internacional), o de la emergencia de la sociedad de la información con avances espectaculares en las tecnologías de las comunicaciones, que han llevado a una verdadera configuración de un único mundo. Pero de no menor calado es la perplejidad de los centros de elaboración cultural y política ante las nuevas condiciones para pensar el mundo. En este sentido, hemos de reconocer sin ambages que el balance de estos últimos catorce años nos presenta una izquierda desorientada que no es capaz de ofrecer respuestas a los problemas presentes, mientras que la derecha ha acepta do mayoritariamente el predominio de los criterios económicos (la esfera privada) sobre la esfera pública, y en concreto sobre la acción política.

B) La política (y muy especialmente la acción política de los partidos y de las instituciones nacionales, regionales y locales) ha sufrido una "colonización" por parte de los medios de comunicación social, y de los poderes económico-mediáticos de quienes dependen aquellos. Son los medios los que dictan la agenda de la política, que cada vez menos es debate de ideas, propuesta de itinerarios, procesos de acción en común y, por último, construcción y ejercicio de liderazgos públicos, para pervertirse como política-espectáculo, ante la que la sociedad reacciona con comportamientos de pasividad e inhibición crecientes.

C) En tercer lugar, no deja de resultar paradójica cierta recuperación de la política "crítica" que se manifiesta en la época más reciente, en dos vertientes diferentes. Por un la do, se está configurando y reconstituyendo un espacio de opinión pública que es muy sensible ante las situaciones críticas ( como ha ocurrido ante fenómenos de tanta gravedad, duración o espectacularidad en España, como el terrorismo en el País Vasco, la catástrofe ecológica de las costas gallegas, o la crisis de Irak). Por otro lado, se ha abierto paso una opinión política "crítica" mundial, hacia los sistemas y con el proceso de globalización económica, que tuvo como punto de arranque el Primer Foro Social de Porto Alegre y se prolongó luego en sucesivos foros regionales ( por ejemplo, el de Génova de julio de 2001, que marcó un punto de inflexión en la opinión europea). Esta opinión "crítica" se manifiesta a veces de forma violenta, lo que en nada favorece su acogida social, pero también está comenzando a dar frutos en 
una línea de pensamiento alternativo que puede concretarse en el lema, cada vez menos utópico, de "otro mundo es posible".

D) Para acabar, más que un signo, una reflexión prometedora sobre la realidad. En los últimos años del siglo XX hemos asistido a una reacción, que va siendo importante, sobre los efectos indeseables que tiene en los comportamientos públicos la secularización de las sociedades tradicionalmente cristianas. Aunque es obvio, hemos de reconocer que el fenómeno de la secularización ha tenido muchos aspectos positivos tanto para la sociedad como más particularmente para la política, así como para la propia experiencia y expresión de la fe cristiana. Pero también ha comportado otros efectos no deseados: el factor católico se ha privatizado y ha perdido casi toda incidencia en el éthos público, ha crecido la insignificancia cultural de la religión cristiana y, como resultado de estos dos hechos, ha aumentado la irrelevancia política del cristianismo.

\section{Algunos presupuestos sobre el catolicismo en cuanto factor político}

De lo que precede puede deducirse que estamos viviendo un momento no sólo de relanzamiento de la reflexión y de la acción política, sino de verdadera refundación de la política; y también que lo cristiano, y lo religioso en general, sigue inmerso en un proceso de búsqueda del lugar y la función que le corresponden en el seno de las sociedades modernas. Para valorar el alcance de esto es útil recordar lo específico de la política frente a otras actividades humanas y sociales: el esfuerzo por construir, mantener y perfeccionar un orden global de convivencia para toda la sociedad, admitiendo como dato de base la pluralidad de cosmovisiones y sistemas éticos que caracteriza a nuestro tiempo. El político no afronta sólo problemas particulares, de los muchos que preocupan a nuestros contemporáneos: se plantea cualquier problema en el marco de ese orden global que sirve de sustrato a la convivencia. Es importante recordar esto, ante el desprestigio evidente de la política que domina en muchos ambientes y la tendencia a buscar alternativas de presencia pública en ámbitos más particulares de la vida social (el desarrollo de compromisos sociales variados y de colaboración con ONGD de todo tipo ilustra esta tendencia).

En este sentido, la dimensión ética de la política es insoslayable. La acción política encuentra su rumbo constante en la defensa y promoción de la justicia, entendida como "virtud" en la que to dos deben ser educados, y como 
"fuerza" moral que sostiene el empeño por favorecer derechos y deberes de todos y cada uno, sobre la base de la dignidad personal del ser humano. Este enfoque está en perfecta armonía con aquel principio inspirador de la enseñanza social cristiana: una política para la persona y para la sociedad encuentra su criterio básico en la consecución del bien común, como bien de todos los hombres y de todo el hombre. Y permítasenos también recordar cómo se concibe en el pensamiento cristiano el bien común: el conjunto de condiciones sociales que permitan a los ciudadanos el desarrollo expedito y pleno de su propia perfección ${ }^{2}$. En resumen: la política existe en función del bien común, en él encuentra su justificación y su sentido, de él deriva su legitimidad primigenia y propia.

Desde estos presupuestos queremos pronunciarnos ahora sobre la acción política y el comportamiento de los católicos en España. Lo hacemos desde un doble estímulo: el que procede de esta coyuntura que entendemos como oportunidad para la refundación de algunas maneras de hacer política y de algunas instancias desde la que los ciudadanos actúan colectivamente; y el que tiene su base en la rica tradición eclesial sobre la política, tanto doctrinal como práctica, aunque su desarrollo haya estado marcado, como toda realidad humana, por luces y por sombras. Porque, si es cierto que estamos asistiendo a una refundación de la política, no quisiéramos que la reflexión cristiana dejase de aportar su experiencia y los valores que ella promueve. Esto es importante para la Iglesia, pero es importante, sobre todo, para la sociedad española. Y para nosotros la cuestión fundamental, la pregunta crucial, no se refiere a los conflictos entre la jerarquía eclesiástica y los gobiernos o a la relación entre práctica religiosa y voto partidista de los españoles. La pregunta crucial es saber qué contribución están haciendo la Iglesia católica jerárquica de un lado y las varias familias de la comunidad de los católicos de otro, a la formación de las capacidades y de las disposiciones favorables para la viabilidad y la calidad de la democracia, y para el desarrollo de la sociedad civil.

El catolicismo es factor político en cuanto se presenta y se estructura como una fuerza social que pretende influir en la sociedad. Pero esta no es una afirmación sólo de carácter fáctico. Tiene además una dimensión ética: el catolicismo aspira a ser factor político porque parte del convencimiento de que el núcleo de valores que nace del Evangelio es relevante para fundamentar la

2 Esta formulación procede de la encíclica cuyo cuadragésimo aniversario celebramos este año: Pacem in terris, de JuAN XXIII, n. 58, que a su vez retoma formulaciones de otros documentos eclesiales anteriores. 
acción política, para buscar el bien común y para conseguir que se cumplan los mínimos de justicia. Esta doble afirmación, que para unos es una evidencia que recoge la mejor experiencia cristiana de los últimos sesenta años y de las enseñanzas sociales de la Iglesia (en concreto, las contenidas en documentos conciliares como la "Constitución pastoral Gaudium et Spes sobre la Iglesia en el mundo de hoy"), para otros puede antojarse más que problemática. Por eso es preciso profundizar un poco más en esta cuestión y preguntarnos: ¿por qué entendemos el catolicismo como factor político?, ¿cómo actúa el catolicismo en cuanto factor político? El catolicismo, en cuanto factor político en la esfera pública, parte de una actitud de crítica de las consecuencias, negativas para el bien común, de una reducción excesivamente privatizadora de la religión, y se sitúa en una actitud de resistencia activa, aceptando las reglas del consenso democrático y de los procedimientos que regulan la configuración cultural en las sociedades abiertas. El catolicismo se reconoce como instancia crítica capaz de contribuir, desde su propio patrimonio, a la configuración de la ética pública.

Algunos sociólogos cuestionan hoy cierta interpretación de las teorías de la secularización. Ésta no siempre lleva aparejada una privatización de la fe. Hoy asistimos a la recuperación del carácter de religión publica para el catolicismo. Hay dos formas de religión pública en que no estamos pensando: el catolicismo puede ser religión pública en cuanto iglesia oficial en un Estado confesional y puede serlo cuando adopta la institucionalización política en un partido, por ejemplo demócrata cristiano. Pero, además de estos modelos, cercanos en el tiempo o en el espacio, el catolicismo puede ser religión pública en aquellos casos en que, aceptando la aconfesionalidad del Estado y la neutralidad respecto a la contienda política, reclama para sí el derecho a intervenir, dialogal y críticamente, en la esfera pública de la sociedad civil. El resultado de esta posición es una concepción de la religión pública compatible con la moderna diferenciación estructural de ámbitos, propia de las sociedades modernas.

El catolicismo puede actuar en la esfera pública por diversas razones. Pongamos cuatro ejemplos. El catolicismo entró en la esfera pública de la sociedad española no sólo para proteger su libertad religiosa, sino, a partir del Concilio Vaticano II, para promover todas las libertades y derechos propios de una sociedad moderna. Algo parecido sucedió más tarde en Polonia, en Filipinas, y en muchas naciones de América Latina. El catolicismo, en segundo lugar, se ha configurado como factor político cuando ha actuado en la esfera pública para cuestionar y contestar la absoluta autonomía jurídica de las esferas seculares y su pretensión de organizarse sin aceptar influencias éticas que 
provengan de otras instancias; en ese caso el catolicismo se configura como una ética pública de máximos, que tiene vocación de contribuir críticamente a la construcción de una ética cívica de mínimos; ése ha sido el caso reciente de los procesos y documentos del episcopado de los EE.UU., cuestionando en los años 80 la "moralidad" de la carrera de armamentos y, más tarde, las inhumanas consecuencias del sistema económico ca pitalista. En tercer lugar, el catolicismo se configura como factor político cuando se hace presente en la esfera pública para defender el tradicional mundo de la vida, abriendo debates sobre la formación de la legislación pública, como ocurre con frecuencia en la promoción de los múltiples aspectos del derecho a la vida, las políticas de recepción migratoria, etc. Por último, el catolicismo es un factor político en cuanto hace la crítica de los modelos no explícitos de religión política, es decir, del uso político de la religión, pretendido o ignorado, tarea a la que, desde los años sesenta, se consagró la teología política europea.

\section{Diferentes actitudes ante la política}

Hemos de comenzar diciendo que somos conscientes de la complejidad de la realidad de la acción política. Por eso preferimos hacer, inicialmente, una distinción simple, pero clara, y hoy habitual, entre la política, como acción de gobierno a través del ejercicio del poder, en nuestro caso concebido y regulado jurídica y democráticamente, y lo político, como ámbito de construcción del sujeto ciudadano que participa en la búsqueda de una sociedad más justa y libre. Es la distinción que, en el ámbito anglosajón, se hace entre polity (la esfera concreta y formal de la política, que se ordena a través de la governance, acción estructurada del poder, y de la elaboración de policies, políticas públicas) y politics (la esfera material abstracta y humana, en que se sitúa la acción y el compromiso de los ciudadanos, el ejercicio de la ciudadanía, la participación democrática y su liderazgo, citizenship).

Muchos de los debates sobre la política parten de una confusa diferenciación de ámbitos, lo que sucede también a la hora de reflexionar sobre el compromiso político y la acción de los católicos. Nos parece más importante, delinear la diferenciación en seis lugares en los que el diálogo y la acción de los católicos se hacen presente en el espacio público. En primer lugar, el cultural en que se elaboran los códigos éticos, los valores y la opinión pública, muy especialmente la prensa escrita y los otros medios de difusión y comunicación social; segundo, la sociedad civil, tanto el diálogo entre unos y otros actores sociales, como la construcción de una sociedad civil cada vez más importante, aunque tantas 
veces frágil, y por ello siempre necesitada de aportaciones que nutran sus valores; tercero, el espacio de la solidaridad social, en el que incluimos la lucha contra la exclusión social, a través de 'voluntariados', de ONGD, y de la cooperación internacional; cuarto, las prácticas militantes que van construyendo los sujetos políticos, y, más concretamente, el momento electoral: en la acción y compromiso políticos es muy importante el tiempo en que son debatidos y elaborados los programas, en que se accede al diálogo entre los votantes y la dirigencia de los partidos y en que se elaboran las candidaturas que concurren a las elecciones en una sociedad pluralista; un quinto espacio es el de los instrumentos políticos que se ponen en función de "liderazgo social" y que son capaces de formular los objetivos de la ciudadanía -o no lo son, y aparece la tristemente famosa perversión de la política como acción en provecho de intereses partidistas o privados, muy frecuente en sociedades menos desarrolladas, pero presente también de forma no menor en Europa en general y en España; por último, la acción política de gobierno: la capacidad de traducir los programas políticos en proyectos de ley y en normas gubernativas, y de elaborar y ejecutar unos presupuestos, a cuyo servicio existirá una burocracia "como racionalización de la acción de poder", en sentido weberiano. Es evidente que no todos los cristianos se sienten igualmente cómodos en estos espacios y que no todos desarrollan las mismas actitudes. Intentamos acercarnos ahora a estas posiciones plurales en el mundo cristiano, ensayando una tipología de las formas de compromiso ${ }^{3}$.

1a) Emigración. Quienes entienden el compromiso político como una actividad completamente secularizada, y quizá profesional, hacen una crítica del mesianismo cristiano y de la inviabilidad de éste en un espacio laico y emigran, puesto que optan por la privatización de su fe, reducida a lo personal y quizás lo familiar y cultural.

2a) Reconfiguración. Quienes aceptando la distinción de planos entre la fe cristiana y la política, han llegado a la acción política a partir de su fe subrayan con fuerza la autonomía de este espacio y enfatizan el pluralismo político de los católicos. Los partidarios de esta autonomía realizan una reconfiguración ético-política, reconocen la inspiración cristiana de sus compromisos y de los valores de sus programas, pero sostienen con fuerza el carácter secular de las mediaciones instrumentales (por ejemplo, los partidos).

3 Para estas reflexiones nos han resultado útiles los escritos en torno al debate italiano de los años 80, así como los de algunos autores, entre quienes queremos mencionar a R.Díaz-SALAZAR, V. Pérez-Díaz, A. Álvarez Bolado, C. Garcia de Andoin y J. Casanova. 
3a) Mediación. Desde mediados del siglo XX han existido tanto en los sindicatos y el movimiento obrero, como en los partidos políticos y otras instituciones de gobierno, quienes han defendido estar como cristianos en el corazón de las masas, renunciando a una presencia visible. Se trata, pues, de una verdadera, al tiempo que falsa, desaparición de los cristianos en la política. Los cristianos, estos 'cristianos de la mediación', no están, no aparecen, en ninguna parte porque están en todas, haciendo de fermento, de levadura, y de puentes de diálogo entre unas opciones plurales y otras, así como en el interior de cada una de ellas.

4a) Presencia. Más tarde, sobre todo desde el final de los años 70 y de la percepción de los frutos de los movimientos "sesentayochistas" en la Iglesia y en la sociedad, pero también gracias al giro más explícitamente afirmativo del nuevo papa Juan Pablo II, un nuevo estilo se ha ido haciendo plaza. Estos cristianos sostienen que, sólo una presencia significativa y relevante, incluida su estructuración en instituciones visibles y poderosas, permite la influencia en la sociedad y la transformación de ésta de acuerdo con los valores evangélicos. En este amplio segmento se mueven tanto quienes abogan por formas con una cada vez mayor tentación neoconfesional, como ciertos "movimientos" que tienden a cerrar las posiciones católicas en ámbitos de resistencia. Esta posición pretende una influencia directa, sin mediaciones, de la ética de máximos cristiana en el entramado cívico.

5a) Radicalismo. La posición de quienes defienden que la aportación cristiana a la política es esencialmente la de un radicalismo ético-político tiene una gran tradición en la historia contemporánea del catolicismo. Desde este radicalismo, palabra que usamos en su más noble y originario sentido, se pretende que la ética de máximos cristiana tenga una traducción directa, aunque no inmediata, en la acción política. Este minoritario, pero muy significativo, conjunto de cristianos es radical en su crítica al capitalismo y en su posición de lucha permanentemente activa por la utopía evangélica. Desde los "socialistas cristianos" del siglo XIX, que enlazan con las más antiguas tradiciones de utopistas evangélicos, y los movimientos radicales de no violencia y de solidaridad con los pobres, los cristianos se han sentido atraídos por ese radicalismo evangélico. Personas como Dorothy Day, Charles Péguy o Simone Weil, se encuentran entre ellos. Muchas de las posiciones defendidas desde la Teología de la Liberación y por movimientos emparentados con ella también nacen en este espacio. No se puede ignorar la importancia de la contribución de esta perspectiva al discurso y a la práctica cristiana de la política. Dos razones deben ser señaladas: la importante tarea de acompañamiento histórico a 
muchos movimientos sociales que ha realizado esta posición, y la capacidad de interpelación crítico-utópica que, desde ésta, siempre se ejerce sobre otras posiciones tentadas de reduccionismo.

6a) Mediación significativa. Esta actitud sintetiza alguna de las anteriores, en diálogo crítico con cada una de sus a portaciones. Creemos que los cristianos deben estar 'en el corazón de la ciudad', iguales a todos los demás ciudadanos, como en su propia patria. Al mismo tiempo que renuncian a una visibilidad externa, los cristianos se configuran como grupo que es capaz de durar en el compromiso ético político y en la transmisión de la fe y de los valores evangélicos. Los cristianos forman comunidades que conservan su memoria en medio de la ciudad secular, aunque siempre conscientes de estar en tierra extraña, sujetos de una peregrinación. Su forma de mediación tiene en cuenta la necesaria disciplina de la libertad y de la lucha por la justicia, y cuida hacerla creíble, duradera, consciente de la complejidad de las mediaciones, especialmente las menos efectistas y las más eficaces. Los cristianos defensores de una mediación densa, deben ser promotores de una significatividad de la raíz y del horizonte evangélicos de su compromiso. Por ello, quienes favorecen este planteamiento han de reconocer la validez de la crítica que subraya que toda opción evangélica acaba siendo insignificante, vaciándose ética y místicamente, cuando no es dialogada y explicitada. Ser levadura, puente para el diálogo y casa común, exige un tiempo y un espacio para la constitución de sujetos eclesiales, personal y comunitariamente capacitados para el compromiso evangélico en la acción política.

\section{El factor político católico en los distintos ámbitos políticos}

El factor político católico y las izquierdas

Comenzaremos diciendo que el plural "izquierdas" indica una diferencia importante. Aunque hay elementos comunes en las dos grandes formaciones españolas, PSOE e IU, también hay diferencias culturales muy relevantes, y concretamente en su relación con el mundo cristiano.

EI PSOE es heredero del fuerte anticlericalismo de los decenios anteriores a la guerra de España ( 1936-1939), que no se corrigió en la época del franquismo. Hubo algunas incorporaciones personales de dirigentes católicos en el PSOE: bastantes de ellos procedían de la Federación de Partidos Socialistas (FPS, 
formada con partidos de ámbito regional, entre los cuales se contaba pequeños partidos socialistas, con fuerte componente cristiana); otros venían de la izquierda de la Democracia Cristiana clandestina. Sin embargo, la cultura política del partido no cambió, y la fe cristiana y su dimensión política fueron considera das cuestiones priva das que no habían de tener casi incidencia alguna en la política de partido. Hay que esperar hasta 1996 para constatar cómo surge con alguna fuerza, sobre to do en el País Vasco (a partir de grupos de militantes cristianos de Euskadiko Eskerra) y en Cataluña, el proyecto de hacer explícita la incorporación de cristianos al PSOE. Un fruto de los numerosos encuentros y debates realizados en esta línea ha sido el libro Tender puentes. PSOE y mundo cristiano 4 .

Por su parte, IU también es heredera de una antigua tradición anticlerical. Sin embargo, ya en los años 60, hubo diálogo y compromiso político de militantes cristianos en organizaciones obreras de la izquierda como CCOO y el PCE. En ese tiempo se vivió una estrecha colaboración, que durante la transición provocó muchas experiencias de convergencia, luchas en común, trasvase de militancia, etc. Todo ello quedó reflejado en el título mismo de aquel libro de Alfonso C. Comín, uno de los teorizadores del movimiento: Cristianos en el Partido, comunistas en la Iglesia.

Pero las diferencias entre ambas formaciones no son sólo temporales: mientras en IU hay una trayectoria de colaboración no interrumpida durante más de 30 años, en el PSOE sólo ahora se empieza a abrir paso este planteamiento, y con un eco más bien minoritario, a pesar de que el $80 \%$ de los votantes al PSOE son católicos, proporción sensiblemente parecida entre los militantes. Es muy distinta también la postura hacia lo cristiano en ambas formaciones políticas. En el PSOE la cultura que ha prevalecido ha sido la de la privatización de las convicciones religiosas y la escasa influencia de la ética cristiana en los planteamientos del partido, y sólo recientemente, en los gobiernos socialistas entre 1982 y 1996, un grupo significativo de cristianos en el PSOE han contribuido a la construcción del Estado de Bienestar en España, en la línea de lo que fue la colaboración entre democristianos y socialistas en la Europa de la posguerra. En cambio, en IU ha sido donde muchos cristianos con aspiraciones más radicales han encontrado cobijo para sus deseos de un compromiso político más marcado por razones humanitarias y cargado de un fuerte idealismo.

4 R. Jáuregui - C. García de Andoin (eds.), (2001). Tender puentes. PSOE y mundo cristiano, Bilbao, Desclée de Brouwer en coedición con la Fundación Pablo Iglesias. 
A la vista de todo esto, ¿cuáles serían las tareas planteadas en la agenda de la izquierda en relación con el mundo cristiano? Enumeramos a continuación las que creemos más relevantes. En primer lugar es preciso hacer más fluida la relación en las culturas militantes con el mundo cristiano en general, y facilitar una mayor colaboración personal entre quienes están en la sociedad civil y quienes están en las instituciones y partidos. Para ello sería recomendable huir de toda tentación de instrumentalización del factor católico, de las instituciones, grupos eclesiales y de las manifestaciones de la vida cristiana en general. Una segunda tarea consistiría en abrirse a un diálogo con los militantes y las organizaciones cristianas en temas a los que éstas son especialmente sensibles o en los que tienen más preparación y conocimiento de la realidad. Pero también aquí es necesario huir de generalizaciones y clichés desde los que frecuentemente se contempla el hecho cristiano y sus manifestaciones, porque de tal manera desfiguran al interlocutor que imposibilitan todo diálogo. Por último, los intentos de apertura y búsqueda de convergencias se ven muchas veces bloqueados por esos resa bios de anticlericalismos que anidan todavía en ciertos reductos de poder de la izquierda: ¿no implican una contradicción muy flagrante con cualquier voluntad de encuentro y diálogo? ¿no constituyen una fuente de sospecha sobre la sinceridad de los interlocutores?

\section{El factor político católico y el centro-derecha}

Tras varias décadas de identificación problemática, pero sociológicamente relevante, de las derechas con el catolicismo, en la transición española se formó un gran partido de centro-derecha más variado en su composición: en él confluyeron casi todos aquellos grupos políticos que en su día pudieron caracterizarse como liberales, demócratacristianos, ciertos socialdemócratas liberales, conservadores, reformistas, e incluso la extrema derecha sociológica. Este partido, que ha llegado a ser hoy el PP, sigue teniendo una fuerte presencia del factor católico, tanto en su electorado como en su militancia; además está integrado en la antigua internacional popular de inspiración democristiana, que en la actualidad es un conglomerado de partidos conservadores y de centro.

Esta heterogeneidad y complejidad de los factores que han convergido en el PP se manifiesta en dos aspectos relevantes y relativamente nuevos del centroderecha español, que en el fondo encierran cierta paradoja. De una parte, se advierte la existencia pública de quienes dentro del PP se proclaman no católicos o desinteresados por el patrimonio ético que procede del cristianismo; a ello se une la emergencia, sobre todo en las generaciones más jóvenes, de un 
talante claramente laicista y de desapego de las propuestas del sistema eclesial al sistema político. Frente a ello asistimos a ciertos intentos de hacer jugar al catolicismo un papel de legitimador de posiciones del PP, que es compañero de un fuerte rechazo hacia el mensaje eclesial cuando éste es crítico con actuaciones del gobierno o del partido.

Estos tres síntomas van unidos a una fragmentación de los católicos en el PP y a una irrelevancia pública de los mismos en la configuración práctica de la política del partido. Es cierto que hay algunas personalidades notables, dentro del partido, de explícita tendencia democristiana, por su formación o por sus orígenes, pero cuesta ver, en la configuración de las políticas del mismo, una expresa aportación de aquella corriente política que quedó ahogada en los primeros años de la transición sin posible futuro en la configuración del mapa político español.

También nos atrevemos a señalar algunas tareas ineludibles en la agenda del centro-derecha español en relación con el factor católico. La primera sería la explícita constitución de un espacio de diálogo dentro del partido para quienes se sienten inspirados en su acción política por la enseñanza social cristiana: un diálogo, tanto con otras corrientes ideológicas del partido, como con el mundo católico de base. Creemos que no basta que existan relaciones entre la Iglesia jerárquica y el Gobierno para que se produzca ese diálogo y ese encuentro. EI PP sigue teniendo pendiente la tarea de "tender puentes" con el mundo cristiano, aunque deba hacerlo desde otra historia diferente a la de la izquierda. Una segunda tarea para la agenda del centro-derecha estaría en la crítica teológico-política que los católicos dentro del PP tienen que hacer de las demandas de legitimación que, desde ese ámbito de centro-derecha, se hacen al mundo católico, tanto a la Iglesia en su conjunto como a las comunidades eclesiales diferentes, estudiando y discerniendo qué aportaciones pueden hacer las diferentes comunidades y familias católicas a la reconfiguración del éthos público y a la refundación de la democracia. Un centro-derecha moderno debería trabajar esa relación, evitando, tanto la huida hacia un simple laicismo conservador, como la ingenua pretensión de comunidad acrítica de intereses y visiones con el mundo católico; y los católicos insertos en él deberían esforzarse por traducir aquellos valores que surgen del Evangelio y de la enseñanza social cristiana para que puedan influir en la propuesta política que haga el propio partido. Dentro de esta búsqueda de traducción de los principios orientadores de la enseñanza social cristiana, nos atrevemos a sugerir que los católicos en el PP deberían destacar en algunas líneas: la preocupación por la defensa de los derechos humanos y por la consolidación de una cultura jurídica que forma 
parte de la mejor tradición democristiana y liberal del centro-derecha, pero también el desarrollo de la sensibilidad social y el apoyo a las políticas transformadoras, de solidaridad y contra la exclusión.

\section{El factor político católico y los nacionalismos históricos}

En la historia y en la configuración actual de los nacionalismos democráticos existentes en Cataluña y en el País Vasco el factor católico ha jugado un papel decisivo. No podemos entrar en el análisis de un fenómeno complejo y cargado de significaciones varias, pero será suficiente constatar algunos hechos. En ambas comunidades el Gobierno siempre ha estado en manos de partidos inspirados por la Democracia Cristiana y pertenecientes a ella. No se olvide que tanto el Partido Nacionalista Vasco (PNV) como Unió Democràtica de Catalunya (UDC) fueron fundadores de la Internacional Demócratacristiana. En Cataluña desde 1980 gobierna una coalición en la que uno de los dos partidos, UDC, tiene una clara inspiración cristiana, aunque no sea un partido confesional, mientras que el otro, Convergència Democràtica de Catalunya, tanto por parte de su militancia como por el relevante compromiso católico de su dirigente, el actual presidente de la Generalitat, recoge una buena parte de la militancia política del mundo católico. En el País Vasco la situación ha sido más compleja y variable, aunque el PNV también ha ostentado la presidencia del Gobierno Vasco desde 1980, sea en solitario, sea en coalición con el PSE durante un largo período, sea en coaliciones dentro del mundo nacionalista, con Euskadiko Eskerra y Eusko Alkartasuna en los primeros noventa, o más recientemente con ésta y Eskerra Batua (IU).

En los años del franquismo, y aún antes, la Iglesia católica y sus instituciones fueron factores de pervivencia y de alimentación del nacionalismo y del sentimiento de identidad del pueblo. Es un tema que ha sido objeto de amplios debates, que podemos resumir de esta forma: muchos consideran que el catolicismo, en cuanto fe religiosa que refiere la vida de las personas ( pero, en cierta manera, también de los pueblos) a la relación trascendente con Dios, ha jugado un papel de moderador del nacionalismo en muchos lugares, y en concreto en los nacionalismos históricos existentes en España. De este modo, el catolicismo habría impedido que esos nacionalismos se configuraran como "grandes transcendencias", y habría consegui do que pudiesen articular la visión nacionalista, siempre tentada de afirmarse como absoluto, dentro de una cierta moderación. Haber logrado que los nacionalismos queden, para la percepción de sus militantes, en la dimensión de "mediana transcendencia" no es un mérito 
menor del catolicismo en cuanto factor católico. El valor de esta aportación se confirma cuando se constata cómo el vaciamiento de toda referencia explícita religiosa ha llevado al submundo del nacionalismo vasco violento a un radicalismo exacerbado que no dispone del límite moderador que supone la religión católica.

También se pueden identificar algunas tareas en la agenda de los nacionalismos en su relación con el mundo católico. En primer lugar, es preciso consolidar este papel político moderador que lo cristiano puede jugar en relación con las aspiraciones absolutas del nacionalismo, como una preocupación, no sólo de la Iglesia, sino de los propios nacionalistas: esta moderación habría de traduci rse también en una capacidad de crítica hacia cualquier intento de presentar como exigencias de un sano nacionalismo lo que, en el fondo, no son sino intereses económicos no exentos de insolidaridad. En segundo lugar, debemos llamar la atención de un hecho que nos parece clave: en esta línea de "desabsolutizar" el nacionalismo, la colaboración con lo cristiano debe aprovecharse para promover, conservar y defender aquellos valores de consenso social, de integración social, de cohesión cívica y de solidaridad con otras realidades territoriales, que pudiesen ser amenazados, y que, de hecho, hoy muchas veces lo están de forma grave en el País Vasco, por encima de cualesquiera aspiraciones nacionalistas por legítimas y democráticas que éstas sean. En tercer lugar, quedará como una tarea a medio plazo la elaboración crítica de una teología política del papel jugado por el factor católico en la configuración de los espacios públicos y políticos de esas comunidades.

\section{Algunos criterios para la acción de los católicos}

En la última parte de este editorial ofrecemos al gunas orientaciones prácticas para los católicos en la arena política. Pensamos, especialmente, en aquellos católicos que colaboran en los distintos ámbitos políticos, sin entrar en las diferencias de sus particulares orientaciones partidistas. Queremos sólo a portar algunos criterios de discernimiento para orientar cristianamente su acción política ${ }^{5}$.

5 Recogemos en este apartado, muy reelaboradas, algunas reflexiones contenidas en el importante discurso a la ciudad de Milán de su entonces arzobispo, cardenal Carlo M. Martini (diciembre de 1995), publicado, por ejemplo, en Sal Terrae 84 (1996) 143-154. En el próximo número de RFS publicaremos el último de los discursos a la ciudad del cardenal Martini, de diciembre de 2002. Sobre estos discursos cfr. Sorge, B., (2002), "Da cristiani in politica. II "decalogo" del Card. Martini", en Aggiorna monti sociali, no 11, 719-730. 
1ํ) Lavalidez dela aportación cristiana desde una visión realista de la política

Hay que comenzar afirmando que el realismo inherente a toda acción política y la utopía cristiana son dos elementos difíciles de casar. Esta dificultad es perceptible en las posturas de muchos cristianos ante la política. Y, sin embargo, ahí radica la oportunidad del cristiano para hacerse presente en la vida política. Por eso, hay que partir de una mirada desencantada sobre la realidad, con capacidad de empatía y de respeto, pero también con un notable talante crítico y sin complejos especiales. Ahora bien, en cuanto reconocemos que cualquier proceso político está caracterizado por una fragilidad y una ambigüedad intrínsecas, podemos descubrir que eso mismo abre en él oportunidades para la humanización de las relaciones sociales y para avanzar significativamente en la promoción de la justicia. Creemos que estamos ya en un momento de mayoría de edad de los católicos en cuanto ciudadanos: por lo tanto, en cualquier ámbito deben actuar siempre con la conciencia de que todo ordenamiento social tiene una condición precaria y provisional.

20) La laicidad de la vida pública como marco para el compromiso cristiano

En cuanto que nos planteamos la presencia comprometida de los cristianos en la vida pública nos topamos con el dato innegable del pluralismo de cosmovisiones que caracteriza a la sociedad moderna. Lo que los cristianos hagan como cristianos, lo habrán de hacer en la mayoría de los casos junto con otros, creyentes de otras confesiones o no creyentes en ninguna fe revelada. Por consiguiente, es ese terreno de la ciudadanía común el que posibilita un diálogo y un esfuerzo para que cada grupo aporte aquellos principios éticos elaborados a partir de su particular patrimonio que puedan ser relevantes para construir una cultura ciudadana común y compartida.

Entendemos que la laicidad de la vida pública conlleva la afirmación de aquellos principios que son comunes y compartidos, eso que algunos han denominado "ética de mínimos". Pero entendemos también que esa laicidad sólo se construye desde las "éticas de máximos", que, nacidas y elaboradas en diferentes "comunidades de memoria", son capaces de aportar su específica contribución al éthos público. Se trata de desarrollar al máximo esa dimensión pública de las éticas de máximos, y más en concreto, de la ética de tradición cristiana.

Así entendida la laicidad de la vida pública, no caben ingerencias indebidas de la Iglesia institucional, del estilo de las que se dieron durante el franquismo, 
de consecuencias tan negativas para las relaciones Iglesia-política en los años posteriores: ¿no encuentran ahí su justificación esos brotes de anticlericalismo que todavía hoy se dejan ver? ¿y no se explica también desde esa experiencia la resistencia de muchos católicos hoy a hacerse presentes en la vida pública? Ahora bien, excluidos esos extremos, hay que afirmar que algo muy importante pierde la comunidad política si los católicos se desentienden o se diluyen en su contribución a la vida pública. Y algo muy importante pierde el cristianismo, en su configuración de fe en el mundo, si renuncia a hacerse presente en la vida pública. Nadie gana en estas retiradas o repliegues de la fe al ámbito privado. Una fe que no se hace compromiso público es una fe muerta, y una vida cívica que ignore o margine las aportaciones de humanización que surgen de la enseñanza social cristiana también se encierra en un círculo pequeño que renuncia a otras aportaciones, que podrían ser esenciales para su vitalidad y su apertura.

Pero la laicidad exige a los cristianos, como condición para legitimar sus pretensiones de presencia pública, excluir todo intento de imposición de sus propias ideas por medios coactivos. En esto hay que dar por definitivamente pasados los tiempos en que la Iglesia, por razones históricas que no son del caso, ocupaba una posición central en la sociedad que la legitimaba para marcar orientaciones de la vida personal y de la organización social. Esto ya es incompatible con las reglas del juego más elementales de una sociedad laica, donde sólo es posible recurrir a la fuerza de la razón y del testimonio como medios para convencer a los demás.

\section{3o) El valor de lo político como espacio para lo cristiano}

Como ya sugeríamos más arriba, muchos cristianos no conciben la política como el lugar más adecuado para el compromiso creyente. Por eso hay que insistir en la necesidad y la validez de la dimensión política del compromiso evangélico. Ello implica huir de las dos tentaciones en que más fácilmente se refugia el cristiano para rechazar el compromiso político, y hacerlo además con la conciencia tranquila: el idealismo y el radicalismo ingenuo. Aunque mantienen algunas diferencias entre ellas, ambas posturas surgen del mismo humus, de gran valor por otra parte: la experiencia cristiana como compromiso urgente por la justicia y a favor de los más pobres y marginados.

El idealismo puede llevar a tal cantidad y calidad de exigencias éticas personales en el compromiso político que, de hecho, torne muy difícil, por no 
decir imposible, el compromiso real de los católicos en las mediaciones políticas existentes. Ningún partido político o institución realizaría las exigencias que brotarían del Evangelio y que serían imperativos para el compromiso cristiano en la vida política. Precisamente por eso -aunque no sólo por eso, porque además hay que admitir el pluralismo político, aun cuando éste no pueda ser ilimitado-, queremos insistir en la necesidad de que el compromiso político cristiano tome cuerpo en situaciones e instituciones discernidas, que siempre serán insuficientes y ambiguas: es el caso de los partidos políticos, los sindicatos, los diferentes niveles de las administraciones públicas, etc.

El radicalismo ingenuo es la otra tentación para el compromiso de los cristianos: consistiría en exigir como distintivo del carácter cristiano de una militancia una insobornable identificación con los "máximos" de la ética cristiana. Hay que admitir que, en algunos casos, ése sea el camino respetable que tomen algunos cristianos. Pero la mayoría van a ser llamados a colaborar en situaciones en que el espesor de la historia y la opacidad de las realizaciones exigirá una alta dosis de paciencia histórica y de renuncia al radicalismo como signo de identidad cristiana. La denuncia profética no puede ser la forma ordinaria de actuar en política, aunque en algunas situaciones sea insustituible. Lo normal habrá de ser el esfuerzo paciente y eficaz para que los valores cristianos vayan penetrando lentamente en la cultura y en los ámbitos prepolíticos a fin de hacer posibles las transformaciones deseadas para una mayor parte de personas.

\section{4)) El compromiso político no puede reducirse a compromiso social}

Aparte de esta doble tentación, otra salida se ofrece no pocas veces al cristiano: la del compromiso so cial como alternativa. Sus posi bilidades son hoy variadas, y su atractivo, ante tanta decepción política, creciente. Esto explica el desarrollo del voluntariado o la proliferación de ONGD; e incluso la inscripción en los partidos más radicales, los cuales, como no tienen ni van a tener responsabilidades de gobierno, pueden permitirse el lujo de lanzar las posiciones ético-políticas más a mbiciosas, de acuerdo con sus convicciones nucleares.

No podemos negar el valor de este compromiso de los católicos que militan en los nuevos movimientos sociales o trabajan en ONGD o en asociaciones e instituciones como voluntarios. Pero hemos de afirmar con fuerza que eso no suple las tareas estrictamente políticas, de creación, mantenimiento y mejora de un orden global de convivencia, ni justifica que los cristianos estén ausentes 
de este ámbito. Porque la dimensión social y caritativa del compromiso de los católicos, con ser tan rica como necesaria, tan válida como digna de todo aprecio, no anula el valor de la política como síntesis de las virtudes públicas y como forma exigente de la caridad. Las distintas formas de compromiso deberían ser vividas por los cristianos desde una conciencia común de la mutua implicación en unos fines, pero en ese conjunto no debe nunca faltar el trabajo en la política institucional. Porque esta es la que suministra el marco normativo e institucional para cualquier otra forma de acción social. La rica experiencia histórica del catolicismo social y de la democracia cristiana, que en los años posteriores a 1945, junto con la socialdemocracia occidental, han construido el Estado de Bienestar habrían de permanecer en la memoria de nuestro pueblo, junto a la enorme contribución de los cristianos en el movimiento obrero, en sindicatos y organizaciones: todo ello ha sido decisivo para la construcción de una sociedad más justa y más equilibrada, territorial y socialmente.

5o) En el compromiso político, ni inmediatismo retórico ni realismo acomodaticio

Hasta ahora hemos hablado de posturas que tienden a rehuir por distintas vías el compromiso político. Pero cuando el cristiano se decide por este, tampoco está exento de caer en algunas posturas extremas: nos referimos al inmediatismo retórico y al realismo acomodaticio. El primero se traduce en la inquebrantable ilusión de que todo es posible y que basta con proclamarlo fuerte; el segundo consiste en un pesimismo conformista que afirma que ninguna meta elevada es realmente asequible.

Ciertos idealismos cristianos mal discernidos pueden llevar a una u otra postura. Por eso hay que evitar, tanto esa precipitación política que bloquea todo proceso que aspire a tener una cierta incidencia política, como un pragmatismo acomodaticio que olvide cuáles deberían ser los objetivos de la acción política propia de los cristianos. Porque para éstos lo prioritario ha de ser buscar cómo transformar en propuestas políticas los valores del Evangelio.

Pero esto no es fácil en un mundo pluralista y complejo como el nuestro, donde lo que el cristiano considera como bien común no siempre puede ser traducido inmediatamente en ley, porque es preciso contar con el consenso de muchos. En una época en la que las evidencias éticas son cada vez más escasas, hay que adoptar como criterio el de una sabia gradualidad. Puede suceder que valores que a unos parezcan preeminentes no sean susceptibles de ser traduci- 
dos en leyes o normas obligatorias de forma inmediata, sobre todo cuando se prevea que su imposición va a suponer una grave deterioro de la convivencia. El principio de integración del cuerpo social debe ser prioritario para la acción política, y resultará decisivo para discernir la legitimidad de determinadas opciones o propuestas. Cuanto más relevante es un valor desde el punto de vista ético, tanto más compromete y, por ello, el proceso para su asimilación social será más largo y complejo. Esto exige un trabajo paciente y concienzudo de mentalización, con buenas razones y ejemplos atractivos, orientados a convencer a la sociedad de la importancia que tendría para ella un determinado valor. Sólo después vendrá la traducción legislativa del mismo.

En todo esto el cristiano tiene que renunciar a ciertas inercias del pasado un pasado ya lejano en el tiempo, pero muy presente en el corazón de algunos. Como hemos dicho más arriba, la Iglesia en la sociedad moderna no posee ya una auto ridad que na die discuta y que le permita definir unos principios morales universales. Pero esto no debe llevar a que desaparezca lo cristiano del espacio público. Debe, más bien, impulsar a los creyentes para hacerse presentes en cualquier plataforma donde estén en debate los grandes interrogantes éticos de nuestro tiempo. Desgraciadamente no es raro que los cristianos, invocando su escasa preparación o paralizados por el miedo o la falta de una elemental audacia evangélica, se resistan a entrar en ese tipo de debates públicos.

60) De los valores evangélicos a las propuestas políticas y a los valores laicos

Los católicos comprometidos deberían ser expertos en transformar en propuestas políticas los valores que derivan del Evangelio y de la enseñanza social cristiana. No basta con abordar los problemas a base de declaraciones de principio; hace falta, además, contar con los instrumentos de traducción práctica de los mismos que desemboquen en propuestas políticas susceptibles de ser compartidas por personas y grupos que parten de otras convicciones éticas. En un mundo plural, vale más la propuesta de caminos transitables por todos, por ser graduales, que el maximalismo, condenado a ser, a medio plazo, políticamente estéril. No siempre la lentitud en los procesos equivale a ceder, renunciando a las propias exigencias. A veces la impaciencia por ver realizadas estas exigencias propias produce justamente lo contrario: que el diálogo se bloquee, o incluso que la situación retroceda a niveles de menos humanización.

Pero hay también situaciones en que el cristiano no puede transigir con ciertas iniciativas que están en abierta contradicción con su visión de la persona 
y de los derechos inherentes a esta. En tales casos su acti tud crítica habrá de ser especialmente vigorosa, aunque nunca podrá pretender que se imponga coactivamente lo que la sociedad no acepta por los cauces de la democracia. Tampoco esto habría de ser una razón para abandonar el compromiso político. De nuevo hay que invocar aquí el principio de gradualidad y seguir trabajando en pro del reconocimiento de esos principios y en defensa de las víctimas en el supuesto de que dichos principios no se reconozcan ${ }^{6}$.

La mediación antropológico-ética es una de las tareas más importantes y urgentes para los católicos comprometidos políticamente y una de las más fecundas aportaciones que las comunidades cristianas pueden hacer a la sociedad. Los principios de la fe deben ser transformados en valores. Dichos valores, que surgen del Evangelio y del proyecto de humanización y de progreso ético desarrollado en la enseñanza social cristiana, deben ser a su vez transformados en valores para el hombre y para la ciudad, con independencia de convicciones religiosas o presupuestos ideológicos. Sólo ese esfuerzo de elaboración cultural y ético-política los hará visibles y significativos, atractivos para otros; y sólo entonces estarán en condiciones de traducirse en leyes o en criterios compartidos para orientar la convivencia de todos.

\section{0) El pluralismo político de los cristianos como hecho y como opción}

Si el pluralismo político es un rasgo distintivo de nuestra sociedad moderna, el pluralismo político de los católicos no es sino su consecuencia: porque la fe, ni aísla del mundo, ni suministra todas las mediaciones para afrontar los problemas concretos que se van presentando. Por eso a nadie extrañará que los católicos sean plurales en sus posturas políticas, y que incluso lleguen a identificarse como tales en grupos específicos dentro de algunos partidos políticos. Pero esa evidencia social es además un principio de orientación práctica reconocido por el magisterio social de la Iglesia desde hace más de treinta años. Permítasenos esta cita del Concilio Vaticano II:

Algunas veces sucederá que la propia concepción cristiana de la vida los inclinará, en ciertos casos, a elegir una determinada solución. Pero podrá suceder, como sucede frecuentemente y con todo derecho, que otros fieles, guiados por una no menor sinceridad, juzguen del mismo asunto de distinta manera. En estos casos de soluciones

6 Todo esto ha sido objeto de una reciente Nota doctrinal sobre algunas cuestiones relativas al compromiso y la conducta de los católicos en la vida política, hecha pública por la ConGREGACIÓN para la Doctrina de la Fe con fecha 24 de noviembre de 2002. 
divergentes aun al margen de la intención de ambas partes, muchos tienden fácilmente a vincular su solución con el mensaje evangélico. Entiendan todos que en tales casos a nadie le está permitido reivindicar en exclusiva a favor de su parecer la autoridad de la Iglesia. Procuren siempre hacerse luz mutuamente con un diálogo sincero, guardando la mutua caridad y la solicitud primordial por el bien común 7 .

\section{8o) El necesario discernimiento de un pluralismo limitado}

No obstante debemos preguntarnos por el estatuto hermenéutico de dicho pluralismo. Muchas veces éste conduce a una fragmentación ilimitada de los católicos y a cierta tendencia a cohonestar cualquier comportamiento político apelando a ese pluralismo. Para nosotros es claro que el legítimo pluralismo católico no puede significar pluralismo ilimitado en virtud de una tolerancia pasiva que rehuye el discernimiento ético: eso sólo conduciría a la irrelevancia de la aportación cristiana, difuminada en una constelación de posiciones todas ellas igualmente respetables. El pluralismo político entre los cristianos no excluye, sino que exige, preguntarse con todo rigor y honestidad si la praxis política concreta es coherente con el patrimonio cristiano, así como llegar a una respuesta que sea razonablemente convincente. No toda opción es igualmente legítima para un cristiano: no basta, por ejemplo, con el hecho de que haya sido tomada por quien se declara cristiano o por alguien que desea ser respetuoso con los valores cristianos. Es preciso asegurarse de que no existe una abierta incoherencia entre dicha práctica y lo esencial de la propia fe. Y esto exige que el creyente disponga de los instrumentos adecuados y la capacidad suficiente para discernir entre una y otra dimensión práctica de su vida: la fe y la política.

En este mismo sentido, algunos creyentes se preguntan si pueden apoyar, con su voto o con la militancia, a partidos que incluyen en sus programas actuaciones no coincidentes con la doctrina católica. La verdad es que resulta muy difícil encontrar un partido cuya ideología y programas sintonicen en todo con la visión cristiana de la vida y de la sociedad. Por eso, el compromiso político implica siempre optar por programas que, en el fondo, resultan insatisfactorios. En tales situaciones, el cristiano experimenta lo que es una sociedad pluralista y laica, que le exige estar presente, no de forma pasiva, sino crítica, y expresar sus puntos de vista siempre que tenga oportunidad para ello. Sólo quedaría excluido de esa opción el caso extremo de un proyecto político cuyo programa en su mayor parte fuera incompatible con la doctrina católica o con los principios éticos.

7 Constitución pastoral sobre la Iglesia en el mundo de hoy, Gaudium et spes, n. 43. 
9o) Diálogo entre cristianos de diferentes opciones políticas

Si el diálogo es siempre difícil, más lo es todavía cuando están de por medio posturas políticas. De esas dificultades no está inmune la Iglesia. Es más, existe verdadera resistencia entre los creyentes a entablar dicho diálogo por el temor, avalado por muchas experiencias pasadas, de que se acabe quebrando la unidad eclesial. Por eso el pluralismo político de los católicos se vive en la Iglesia desde una postura de ignorancia, cuando no de indiferencia.

Aceptando el realismo de esos temores, no podemos dejar de sentirnos incómodos ante sus consecuencias: porque, por este camino, algo que venimos considerando central en el compromiso cristiano queda automáticamente excluido de la dinámica de las comunidades eclesiales. Si el compromiso político del cristiano es tan importante, ¿no habría que buscar espacios donde los creyentes pudieran debatir y dar razón de sus propias opciones políticas? ¿no sería esa una ocasión inmejorable para poner en práctica algo tan propio del cristiano como el discernimiento, en cuanto búsqueda de lo que Dios quiere de cada uno en la situación particular en que vive? Una Iglesia madura es aquella en que sus miembros, no sólo se atienen a los principios y normas que son comunes a todos, sino que buscan su respuesta personal a la llamada que sienten de Dios.

Lo que estamos sugiriendo es que existan instancias, de matriz cristiana 0 explícitamente eclesiales, donde sea posible un diálogo entre quienes militen en diferentes opciones políticas. Los frutos de este diálogo serán múltiples: someter a la crítica las propias opciones y purificarlas a la luz de la fe y de las opciones diferentes de otros; ayudarse mutuamente a trabajar de modo coherente con los valores que son comunes a todos; formular criterios de discernimiento político en general; elaborar ciertos criterios comunes de orientación de la praxis política en aquellos terrenos en los que el legítimo pluralismo no puede ignorar que están en juego algunos valores estrechamente ligados a la entraña del Evangelio.

Este último punto lo consideramos hoy de especial trascendencia. Nos referimos, por ejemplo, a la promoción y tutela de cuanto se refiere a los derechos de la vida en situaciones límite o en nuevas fronteras de investigación, como ocurre en las prácticas y en la legislación sobre interrupción del embarazo, un final digno de la vida humana o ensayos terapéuticos con embriones. Piénsese también en la libertad de expresión y de llevar una vida pública digna y en libertad de muchos ciudadanos en el País Vasco. No menor es la importancia de cuestiones tales como la defensa de logros esenciales del Estado 
de Bienestar ante el posible deterioro a que se ven sometidos por prácticas que cada vez más buscan la rentabilidad a corto plazo 0 , finalmente, las políticas justas de acogida e inserción de inmigrantes. Por último son muchas las exigencias derivadas de la libertad de enseñanza reconocida como derecho efectivo para las ciudadanos: el derecho a promover centros de iniciativa social, la elección de los mismos sin que hayan de superar obstáculos indebidos, la misma posibilidad de que en las escuelas de titularidad y gestión pública se garantice el derecho a que los ciudadanos reciban una educación, constitucionalmente garantizada, en su núcleo de creencias y valores.

\section{Conclusión}

Hemos abordado una cuestión que no esfácil. Por eso el editorial ha resultado especialmente extenso, a pesar de que hemos prescindido de algunos puntos que hubieran servido de complemento a lo escrito. Nuestro deseo no ha sido formular una última palabra sobre cuestiones tan debatidas, sino tan sólo reavivar la inquietud por el tema, en un momento histórico en que se dan ciertas condiciones para ello, y ofrecer nuestras reflexiones como una invitación a que nuestros lectores reflexionen también en confrontación con su experiencia propia o ajena.

Como hemos dicho en al guna de las páginas que preceden, las comunidades eclesiales están faltas de espacios para abordar con serenidad estas cuestiones, que quedan irremisiblemente abandonadas a la conciencia particular de cada uno y sin posibilidad de confrontarse con otros que actúan desde la misma fe. Tampoco en ambientes laicos suele mirarse con buenos ojos la presencia de los cristianos y el diálogo con ellos.

Ante estas constataciones, el edi to rial que ofrecemos y la Revista de Fomento Social que lo publica, que en sus últimos treinta años no ha dejado de ocuparse de estos temas, quiere ser un lugar de encuentro abierto a todos, creyentes o no, interesados en que este diálogo se establezca, progrese, se purifique y dé los frutos que se pueden esperar de él. 